\title{
$1 \quad$ How much cement can we do without? Lessons from cement material flows in the UK
}

\author{
W. Shanks ${ }^{\mathrm{a}}$, C. F. Dunant ${ }^{\mathrm{a}, *}$, Michał P. Drewniok ${ }^{\mathrm{a}}$, R. C. Lupton ${ }^{\mathrm{a}}$, A. Serrenho ${ }^{\mathrm{a}}$, Julian \\ M. Allwood ${ }^{\mathrm{a}}$ \\ ${ }^{a}$ Department of Engineering, University of Cambridge, Trumpington Street, Cambridge CB2 1PZ, UK
}

6 Abstract

Cement manufacture is responsible for 5-7 \% of world $\mathrm{CO}_{2}$ emissions. Cement is primarily used in concrete, the most used material on the planet and a critical part of any analysis of emissions reduction strategy. To estimate the potential for reducing demand, this work analyses material flow in the cement industry, using the UK in 2014 as a case study. Combining published data, analytic assumptions, and interviews we estimated the material flow of cement from the production to a breakdown of its use in applications. Having broken down the demand for cement into 25 applications, multiple material efficiency techniques were considered: substituting cement for calcined clay and limestone, reducing the cement content of concrete, post-tensioning floor slabs, using more precast building elements, reducing construction waste, and reducing the overdesign in construction. We produce a final estimate of the total reduction in emissions achievable from material efficiency: $51.3 \%$. Due to overlap and interactions between the methods, the attribution of the carbon abatement depends on the sequence of application. In this analysis, we have applied the reduction of overdesign last, because it is independent of the others, and would require a cultural change. We show then that cement demand from floors, repairs and maintenance, concrete beams, and applications within the transport sector should be targeted. The substitution of cement with calcined clay and limestone has the biggest potential to reduce cement demand (27\%) and carbon emissions in the UK. Reducing the amount of cement in concrete has the next highest

\footnotetext{
${ }^{*}$ Corresponding author
} 
potential (10\%), followed by post-tensioning floor slabs (3\%).

Keywords: Material efficiency, Material Flows, Cement, Carbon emissions

\section{1. Introduction}

Cement is the most consumed material in the world (Low, 2005). We make more than four billion tonnes of it every year $-560 \mathrm{~kg}$ for every person alive (van Oss, 2017). It is one of society's most ubiquitous, cheap and useful materials. Mixed with water and sand it makes mortar, or more commonly it is used as a binder in concrete which. Producing clinker, the primary ingredient in cement, requires heating limestone to $1450^{\circ} \mathrm{C}$. Burning fossil fuels is the predominant method used to provide energy for the process, accounting for 40-50 \% of emissions; additionally, limestone decomposes upon heating, accounting for the remaining 50-60\% (Van den Heede and De Belie, 2012). These emissions account for 5-7 \% of global $\mathrm{CO}_{2}$ emissions (Mathieu, 2006); in the UK this value is about $1 \%$ (UK Government - Department for Business, Energy and Industrial Strategy, 2016). Cement demand is projected to increase (International Energy Agency, 2018), so its manufacture is key in any global decarbonisation pathway. Efforts to reduce the energy-related emissions include reducing the dependence on fossil fuels and research into carbon capture and storage for cement plants. Further strategies involves reducing the process emissions of cement by reducing demand for clinker using fly ash (FA) and ground granulated blast-furnace slag (GGBFs) or capturing the $\mathrm{CO}_{2}$ released.

Process and energy related emissions. Much of the progress in decarbonisation has been made in energy-related emissions and the potential for further efficiency improvements appears to be limited. Clinker is produced in cement kilns whose energy intensity can vary widely. However, globally. only $14 \%$ of clinker is still produced outside of dry kilns, in wet kilns which have to supply additional energy to evaporate water. There is therefore limited scope for further improvement (World Business Council for 
Sustainable Development - Cement Sustainability Initiative, 2016). Waste heat can be captured from cement kilns and used to generate 'green' electricity, to the order of about $30 \%$ of input heat (World Business Council for Sustainable Development Cement Sustainability Initiative, 2016; Schneider et al., 2011). This estimation appears optimistic, however, and in the UK, no significant opportunities to exploit kiln waste heat have been identified (Department for Business, Energy \& Industrial Strategy and Mineral Products Association, 2017). Electricity demand accounts for up to $10 \%$ of the $\mathrm{CO}_{2}$ emissions associated with cement production (Van den Heede and De Belie, 2012). This has been mitigated to some extent with on-site renewables and demand-side flexibility. However, any possible further improvement here is minimal: a case study of an optimised electricity schedule was found to reduce electricity-derived emissions by only $4 \%$ (Summerbell et al., 2017). Providing heat with biomass or waste instead of fossil fuels is a further method to reduce greenhouse gas emissions associated with cement production. While this switch has been partially achieved in the UK, Griffin et al. (2014) argues that availability of waste fuels and competition for biomass may be a limiting factor.

More than half of the carbon emissions released by cement manufacture are 'process' emissions from the thermal decomposition of limestone. Carbon capture and storage (ccs) is one way of mitigating these emissions, whereby $\mathrm{CO}_{2}$ is captured and stored underground after it has been produced ( $\mathrm{Li}$ et al., 2013). The International Energy Agency predicts that ccs could reduce global emissions from cement production by $56 \%$ on today's value (International Energy Agency and The World Business Council for Sustainable Development, 2009). ccs is currently an immature technology, particularly with respect to cement manufacture: there has so far been no industrial-scale demonstration of the technology on a cement plant anywhere in the world. In the UK, only one kiln has a large enough throughput to be considered economically viable for ccs retrofit (Griffin et al., 2014). Pathways to decarbonisation cannot confidently rely on ccs technology. 
Material and supply-side options. Clinker substitution is a successful and established mitigation strategy. Fly ash (FA), a by-product of coal-fired power plants, and ground granulated blast furnace slag (GGBFs), a by-product of the steel industry, are both suitable for this purpose (Leese and Casey, 2015). These materials do not alter the process emissions from producing clinker, but have significantly lower embodied emissions than clinker, and in reducing the need for it they lower the embodied emissions of the final material used. Currently, they account for about $20 \%$ of cementitious material used in the UK cement and concrete industries. This has significantly reduced the emissions intensity of UK cement: Portland cement (Portland cement) embodies $0.930 \mathrm{~kg}$ of $\mathrm{CO}_{2}$ for every $\mathrm{kg}$ made, while the average embodied emissions associated with uK cementitious material is $0.787 \mathrm{~kg}$ - a $15 \%$ reduction (Leese and Casey, 2015). There are however limitations on the availability of these materials, both in the UK and globally (Damineli and John, 2012). The International Energy Agency and The World Business Council for Sustainable Development (2009) estimate that globally clinker substitution with these materials can only account for a reduction in emissions of $10 \%$ on today's value.

Griffin finds that in the UK, under a 'radical transition scenario', emissions will only be reduced by $50 \%$ on 2010 levels by 2050 whereas the entire economy needs to decarbonise by about $70 \%$ to adhere to the 2008 Climate Change Act (Griffin et al., 2014; Government of the United Kingdom, 2008). The decarbonisation of the cement sector cannot be achieved without improving material efficiency (Allwood et al., 2011) and reducing demand. There are numerous studies that consider individual methods of reducing cement demand from a specific application — using ultra-high performance concrete (Wille and Boisvert-Cotulio, 2015) or post-tensioning of concrete floor slabs (Abdelrahman, 2017) — but there are no wider analyses of which efficiency techniques have the greatest potential, or which the easiest to implement might be.

Some work has attempted to evaluate how cement is used. For example McEvoy 
et al. (2004) have applied a 'mass balance approach' to construction material flow in the North West of England estimating construction materials' destinations by endsector. Similarly, a breakdown of construction materials in Ireland into their end-sector proportions is given by Woodward and Duffy (2011). Their study describes the mass flows of ready-mix concrete, concrete blocks and other prefabricated parts. The authors also consider the end of life and the waste management stage of the industry. However, their work does not detail finely the final applications of cement. Wang et al. (2016) analyses flows in the Chinese cement industry. Their study gives numerical relationships between inputs and outputs in relevant processes. However, in their analysis, cement products are only broken down into mortar and concrete. There are multiple instances of material flow analyses of specific elements of the cement life cycle. For example, Gao et al. (2016) aim to quantify mass flows in the clinker production process. Broadhead (2017) performs a material flow analysis on the global life-cycle of cement but with limited resolution in end-use applications and does not quantify material efficiency benefits.

To aid planning and life cycle analysis, Kapur et al. (2008) modelled stocks of cement in the United States. Their study achieved higher resolution of cement's enduse than those previously mentioned: it broke the uses of cement down in to 'end-use markets' such as water and waste management, commercial buildings etc. Unfortunately, this resolution is insufficient to assess material efficiency improvements, which depend on applications. Similarly Cao et al. (2017b) propose a wide historical and prospective view of the use of cement at the scale of countries. Cao et al. (2017a) modelled of the stocks of cement in end-sectors in China. However, no estimation of the stocks within individual applications was reported. Also studying China, Fernández (2007) broke material consumption in urban areas down into different types of construction. Unfortunately, the results were not specific enough in terms of applications to aid this study. 
Currently, there is no holistic understanding of the techniques that could improve cement use, nor do we have the knowledge to assess which of these techniques could have the biggest effect. This work aims to fill this gap, by:

- understanding where cement is used and the processes involved in going from raw materials to detailed applications

- quantifying, by application, the extent to which demand can be reduced through various 'material efficiency' techniques

- verifying the results of this analysis with the construction industry.

Using the results of this analysis, recommendations can be made as to which applications should be targeted and which material efficiency measures could have the biggest impact. These recommendations should be realistic and implementable; uncertainty in the analysis is assessed where possible and the limitations of the proposals are discussed.

\section{Methods}

This section details the methods used to map the flow of material in the cement industry in the UK. Subsequently, material efficiency measures and their effects on demand and carbon emissions are assessed on an application-specific basis. An estimate of the total possible reduction in cement demand and resultant emissions savings is also derived.

\subsection{Mapping material flow}

Material flow analysis (MFA as per Brunner and Rechberger (2003)) was used to build a map of the flow of materials in the cement industry, from raw materials to end-use applications. Published data were used to map from extraction to cement production. The uncertainties associated with these data were estimated so that more reliable data could be identified and contradictory sources compared. Case studies, relationships and 
estimation were used to estimate the breakdown of demand for cement from its final applications.

Defining the system boundary. System boundaries must be specified to avoid incorrect inclusion or exclusion of data. The uK's cement industry was chosen as the area to be studied: data are much more widely available there than globally. The time frame studied was 2014 as this was the most recent year with data widely available. Occasionally, data for other years had to be used, either under the assumption that the value does not change significantly year on year, or by scaling up from bottom-up samples.

Defining the system structure. Limestone or dolomite or chalk (or a mixture) and clay or shale are mined. In 'raw meal processing', they are crushed and milled into fine particles, then dried. This raw meal is fed into a kiln and heated to $1450{ }^{\circ} \mathrm{C}$ by burning fuel. In the kiln, several chemical reactions occur, releasing $\mathrm{CO}_{2}$, kiln dust and the desired product, clinker, which is a mixture of calcium aluminates and calcium silicates. Clinker is cooled and ground into a fine powder with 0-5\% gypsum. The resulting grey powder is Portland cement. Small amounts of FA, GGBFS or limestone fines can also be added at this blending stage. This process is the so-called 'dry bed process' which is to our knowledge the only one used in the UK.

Portland cement can then be mixed further with the additions FA and GGBFs to alter its properties and reduce the final product's embodied carbon. This can be done either at the cement plant, or during concrete production. In the eu there are 27 different types of cement, based on their proportions of clinker, gypsum, FA, GGBFs, limestone and other materials. Each type falls into one of five classes (CEM I-v ${ }^{1}$ as per EN BS 197-1).

Cement is then mixed with fine aggregates (sand), coarse aggregates (gravel) and water to make concrete, or without coarse aggregates to make a paste called mortar. Concrete production can occur in three main ways: ready-mix, where the wet mixture is poured 'in-situ'; precast, where concrete products are made in a factory then assembled

\footnotetext{
${ }^{1}$ CEM I is the same as Portland cement.
} 
on-site; or retail, where cement is bought in bags and mixed at a small scale (this ranges from small do-it-yourself project to small amounts of mortar mixed by contractors). While it makes up only 10-15\% of concrete's mass, cement accounts for $80+\%$ of its carbon emissions (in the case of CEM I) (Dewar, 2003; Teh et al., 2017). This investigation is motivated by carbon emissions and so cement and its ingredients were the materials tracked in the MFA. Water and aggregates, concrete's other constituents that account for far less of the overall emissions, were not. Figure 1 illustrates the path from raw materials to structure, and indicates where the material efficiency techniques proposed in this paper would apply.

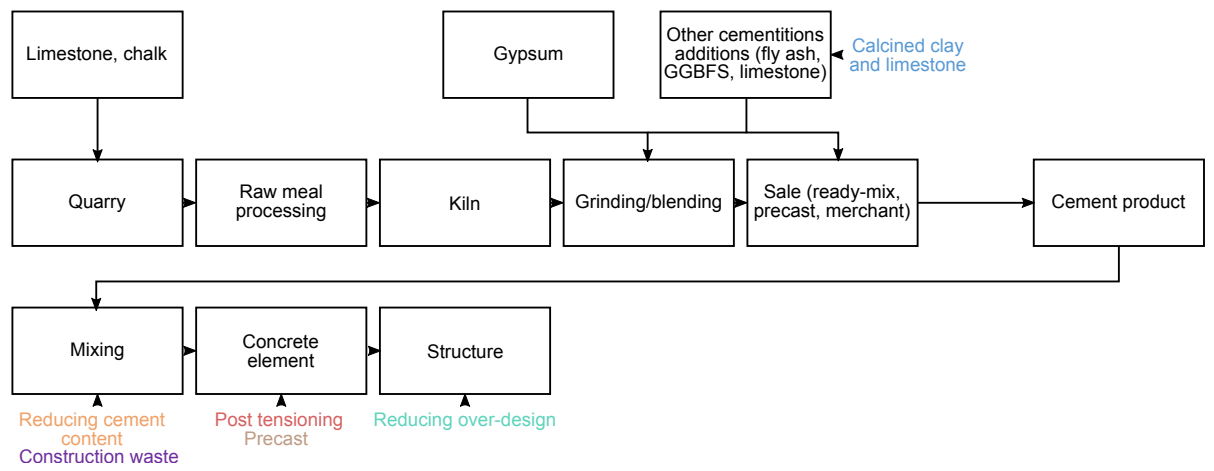

Figure 1: Flow diagram illustrating the cement industry processes and materials studied in this MFA. We have also added the points at which the material efficiency techniques would intervene.

Key assumptions. Data sources rarely specify which cement class is used, let alone give a breakdown of cementitious materials used. Some concrete products are typically made with a specific class of cement. For instance, concrete in very large foundations will use GGBFs to reduce the heat of hydration and prevent cracking (Sun et al., 2013; Tang et al., 2015). This kind of information is not available for most applications. In Part II of the MFA, all cement and cementitious materials were aggregated into one material, therein labelled 'cement' and it was assumed that this single material was used in all applications.

Additionally, the amount of cement in concrete varies from product to product 
(usually $200-300 \mathrm{~kg} / \mathrm{m}^{3}$ ) and is not always specified. The cement content depends on location, temperature, availability of other materials (such as high quality aggregates) and can also vary due to human interference on site or designers' choices. Therefore, data on concrete production and concrete use in specific applications do not necessarily translate directly to cement use in that application. Where it was necessary to work backwards from concrete data to cement use, an average cement content had to be assumed.

Performing the MFA - Part I: From raw materials to cement. The first part of the MFA required mapping material flows from extraction through various processes to the production of cement, and the forms in which it is sold: precast, ready-mix or small-scale 'retail' cement. This was done by collecting and harmonising published data to form a coherent map. Uncertainty here was estimated, and any missing data accounted for.

Data are reported on raw material extraction, material throughput of kilns, clinker production and broadly the use of additions. Nearly all cementitious material flow in the uK is covered by these data, which were collated in a database. Their sources are summarised in Table 1. The sum of all raw materials, plus additions, less the waste from the production of clinker comes to 13,030 kt. The Mineral Products Association estimates that total cementitious material used in the cement industry in Great Britain in 2014 comes to $12,433 \mathrm{kt}$. When scaled by population (Great Britain comprises $\sim 97 \%$ of the population of the UK), this translates to material use of $13,040 \mathrm{kt}$ in the $\mathrm{UK}-\mathrm{a}$ strong level of agreement.

For this part of the MFA, the uncertainty associated with each data point was estimated. There are multiple possible sources of uncertainty in material flow analysis, described below.

Unavailable data There are no available data for certain flows, either because they are not recorded, or because they are not released for competitive reasons.

Data reporting Data can be reported in a number of different forms: production quan- 
Table 1: The sources of data used in Part I of the MFA.

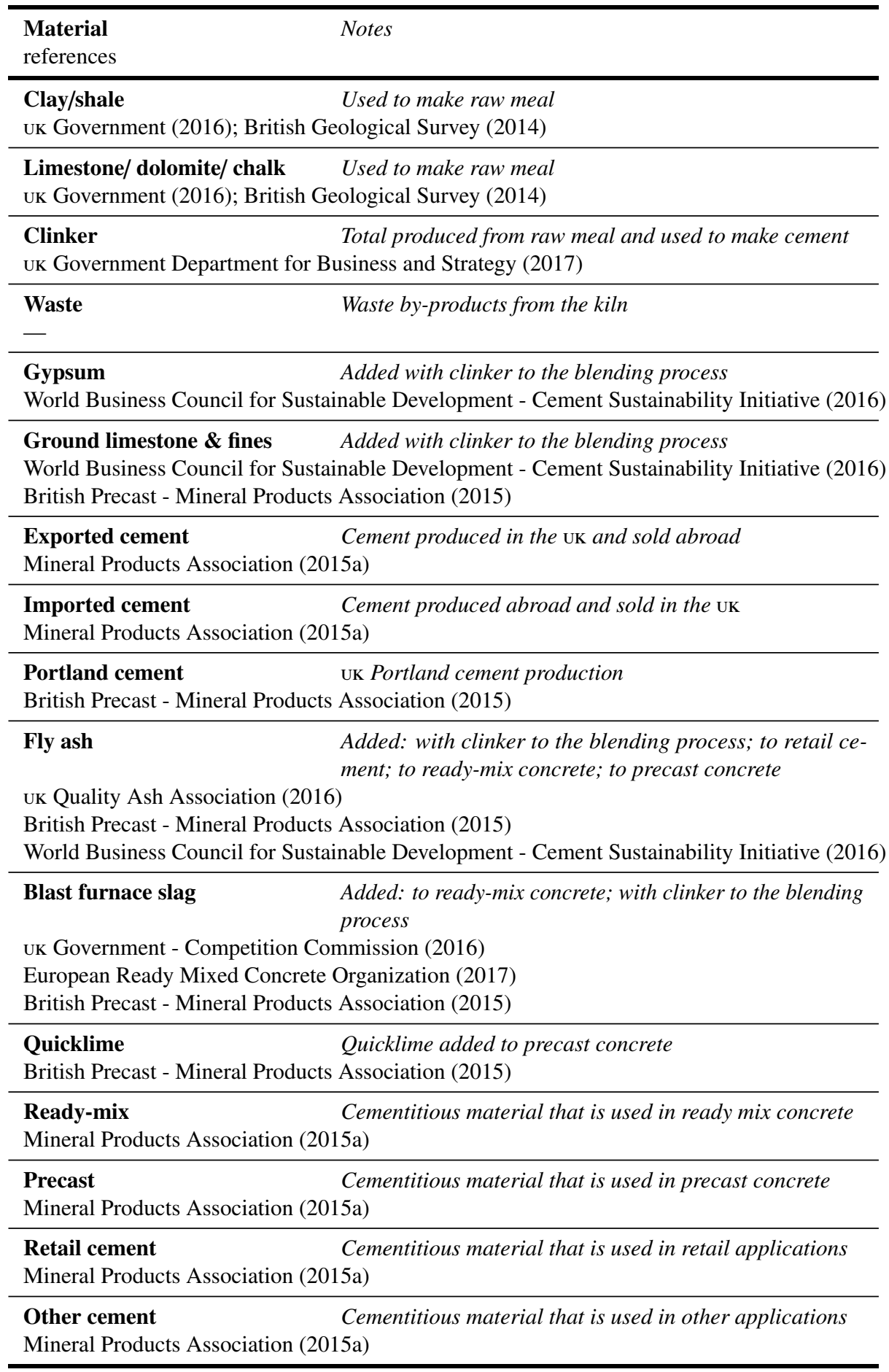


tities, sales, deliveries or stocks. For a consistent MFA, the differences between of each of these should be considered. Because cement has a relatively short shelf-life, stocks are generally sparse and data are usually reported as sales.

Anachronous or foreign data The best available data may fall outside the system boundary. This data can be included in the MFA, but appropriate consideration of the uncertainty that this produces is necessary. Some data were reported for Great Britain (Scotland, Wales and England). The subject of this study was the United Kingdom (Great Britain + Northern Ireland) so to account for this disparity, when no data could be found for Northern Ireland, values were scaled with population. This adds about $3 \%$ onto the mass flow. Due to the relatively small change, errors introduced here should be small.

Clarity of data It is not always clear what the data are referring to, especially in an industry like cement's which can be complex due to the number of different materials involved.

Estimating the uncertainty the uncertainty of each data point was characterised by using the method of Laner et al. (2015) to systematically quantify coefficients of variation (CVs). Assuming uncertainties are described by normal distributions, the $\mathrm{CV}$ is the ratio between the standard deviation $s_{i}$ and mean $X_{i}$ of each data point $i$ (Equation 1), with the true value expected to fall within $2 s_{i}$ of the mean $95 \%$ of the time.

$$
\text { Coefficient of variation } \mathrm{CV}_{i}=s_{i} / X_{i}
$$

The coefficient of variation for each data point was determined by scoring each data source from 1 (very good) to 4 (questionable quality) on its reliability, completeness, temporal correlation, geographical correlation, and other correlation (e.g. similarity of material categories). To yield a quantified uncertainty 
characterisation these scores were mapped into CVs according to Equation 2:

$$
\mathrm{CV}= \begin{cases}a e^{b \cdot \text { score }} & \text { for the reliability category } \\ a e^{b \cdot(\text { score-1)}} & \text { for other categories with score }>1 \\ 0 & \text { for other categories with score }=1\end{cases}
$$

with default settings of the parameters of $a=0.375$ and $b=1.105$ (Laner et al., 2015). Finally, to give a single CV representing all sources of uncertainty for the data source, the individual CVs were combined according to Equation 3:

$$
\mathrm{CV}_{\text {total }}=\sqrt{\sum_{c \in \text { all categories }} \mathrm{CV}_{c}^{2}}
$$

Manipulation of data and 'reconciliation' was performed when multiple sources report on the same flow. If these sources are judged to be in general agreement relative to their size, an average flow, $f$, can be found which is also characterised as a normal distribution with mean $X_{f}$ and standard deviation $s_{f}$. This is done according to Equations 4.

$$
X_{f}=\sqrt{\frac{\sum_{i}^{n} \frac{X_{i}}{s_{i}{ }^{2}}}{\sum_{i}^{n} \frac{1}{s_{i}{ }^{2}}}} \quad ; \quad s_{f}=\sqrt{\frac{1}{\sum_{i}^{n} \frac{1}{s_{i}{ }^{2}}}}
$$

This method was used for the masses of FA and GGBFs being added in the production of Portland cement, FA added in the production of Portland cement, GGBFs added to ready-mix concrete and FA added to precast concrete.

Occasionally the mass flows reported by data sources disagree sufficiently that the average could not be a reliable representation of the true value. There are several possible reasons why they do not agree: they are erroneously labelling the same flow but are in reality referring to different ones (e.g. one is referring to total cement while the other to only CEM I), one is an estimate while the other is based on measurement, or one is simply incorrect. In these cases, the uncertainty estimates were used to decide 
which the more reliable source was, with the others being ignored. This was necessary for the masses of limestone/dolomite/chalk and clay/shale used to make raw meal.

Performing the MFA - Part II: From cement to applications. No data are published on the demand for cement for any application. The methods used in this part of the MFA were an attempt to estimate this information, and are described below grouped by end-use sector. An application is an individual product that cement is used in (e.g. mortar for bricks, dense concrete blocks, foundations etc.) The relevant features of an application are: end-use sector (residential buildings, non-residential buildings, infrastructure, repairs and maintenance, other), building type (if applicable), building frame type (if applicable), and the material it is made from (concrete, non-concrete, unspecified). The applications included in the MFA were generally dictated by the availability of data; applications for which there was no way of estimating cement use were grouped into an 'other' category.

Data on concrete demand from each end-use sector was provided by CEMBUREAU (2017). This source supplied data for the un for 2007-2009, so errors will have been introduced when assuming that they apply to 2014 , due to the inevitable changes in demand over time. To check that these data are accurate, they were compared to the financial outlay in 2014 of the relevant construction sectors published by the Office for National Statistics (2015). These data align extremely well, due to economic conditions in 2014 being at the level of 2008 see e.g. Office for National Statistics (2018b,c). The CEMBUREAU data were therefore considered a sound basis from which to underpin other calculations, under the assumption that industry spending and concrete demand are correlated. Following this, the breakdowns of cement use within each sector were calculated.

Concrete in steel- and concrete-framed buildings A breakdown of the uses of cement within buildings is needed. The relative use of concrete in beams, columns and floor slabs in a concrete framed building was given by a case study from 
the Singapore Building and Construction Authority (2012), and confirmed as being accurate by industry experts. Concrete ground floors were approximated as $150 \mathrm{~mm}$, while a regular (first floor or above) slab is approximately $280 \mathrm{~mm}$ (Neal, 2002; Eyre, 2006).

To calculate the cement demand from columns, we calculated the mass of slabs required, assuming a load of $5.5 \mathrm{kN} / \mathrm{m}^{2}$ after Coelho et al. (2004), for buildings up to 10 floors. A spreadsheet was made which calculated, for buildings of height from 1-10 floors, the mass of the floor slabs. From this and the case study above, demand for cement in columns and beams can be estimated. Cement demand in foundations for concrete-framed buildings can then be estimated as a function of the weight and live load of the building (assumed to be $5 \mathrm{kN} / \mathrm{m}^{2}$ (Formichi, 2008)), using a representative soil load-bearing capacity of $150 \mathrm{kPa}$, and assuming point load transfer from columns to foundations. The foundations can be approximated as cubes just large enough so that the pressure imparted on the soil will not cause it to collapse. Larger buildings will use piles and/or rafts, but these only represent a small fraction of all construction. The foundation size for a particular building therefore depends on the floor area and number of storeys. The results given by the spreadsheet were not very sensitive to slab self-weight, and were minimally sensitive to the assumed live-load.

This breakdown varies with number of stories; an average breakdown was calculated using the building heights distribution shown in Figure 2. To test the sensitivity of this breakdown to the building height distribution, it was shifted 'upwards' -3 storeys were added on to every building such that the mean floor height was 6.13. The shares between floors, foundations, columns and beams in the final breakdown changed by $<1 \%$ each (the relative shares between ground floors and floor slabs did change more significantly, however similar material efficiency techniques can be applied to these applications so this uncertainty is 


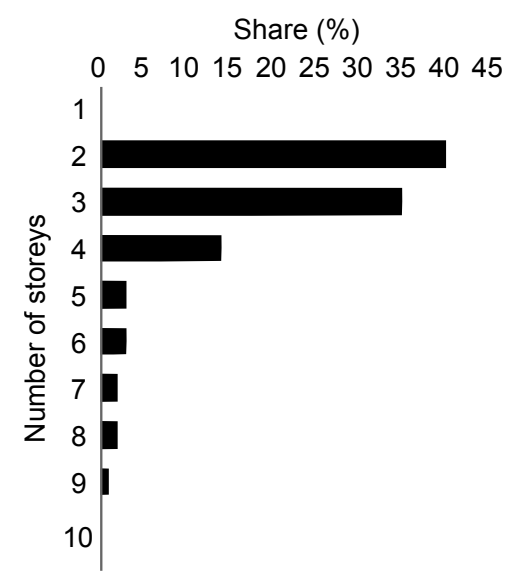

Figure 2: The distribution of building storey-number for steel- and concrete-framed buildings used in this analysis, adapted from the UK Government (2010) (p. 11). This source reported the share of flats of storey height $1-5,6+$, and is assumed to apply to all non-residential buildings as well because no data on heights of offices etc. are reported. The mean number of storeys in this distribution is 3.13 .

not critical).

It is difficult to estimate how much concrete is used in cores. It was assumed that cores are only used in concrete frames above around 15 floors. This would mean that few buildings have a core; a total demand of $3 \%$ within a concrete frame was used as an estimate. The breakdown was verified during interviews with design engineers, and found to be in agreement with their numbers. Further, for a seven story concrete-framed building, the output of this method aligns extremely well with a case study by López-Mesa et al. (2009).

The relative proportions of concrete use between floors, foundations and cores for steel-framed buildings was done in the same fashion as for concrete-framed buildings. For every building height of 1-10 storeys, the mass of foundations was calculated based on the mass of concrete floor slabs and live-load capacity required, assuming that the mass of steel elements would be minimal compared to these slabs. It was difficult to calculate the amount of concrete used for cores; they are generally used for steel buildings above about 8 storeys and a $6 \%$ share was used as an approximation. 
Concrete blocks The annual production areas $\left(\mathrm{m}^{2}\right.$ of face) of the three main types of concrete block — lightweight, dense and autoclaved aerated (AAC) — are published by the uK Government Department for Business and Strategy (2017). Assuming an average block volume of $440 \times 215 \times 100 \mathrm{~mm}(\mathrm{CBA}, 2008)$, the number of each type of block can be calculated. A survey of concrete blocks provided their average masses: $20 \mathrm{~kg}, 25 \mathrm{~kg}$ and $14 \mathrm{~kg}$ respectively. The cement content by mass of the three types of block was kindly provided by John Mason of Thomas Armstrong Ltd. as "somewhere between 7-12\% by weight typically. For instance, a dense block requires less cement than a lightweight block due to the stronger, heavier aggregates used" (Mason, 2018). Dense, lightweight and AAc blocks were assumed to be $7 \%, 9.5 \%$ and $12 \%$ cement by mass respectively. Subsequently, the cement demand from each type of concrete block can be found:

$$
\begin{aligned}
\text { Cement in blocks }= & \frac{\text { Area of block produced }}{\text { Average area of block }} \times \text { Average mass of block } \\
& \times \text { Average cement content of block (by mass) }
\end{aligned}
$$

Infrastructure Cement's infrastructural applications in the Eu were broken down into transport, hydraulic works (pipes) and other infrastructure by CEMBUREAU (Rimoldi, 2017). This breakdown was developed further by assuming that cement use within transport applications is directly proportional to spending in the UK construction sector (Office for National Statistics, 2015), and that we do not use cement in roads.

The amount of cement in paving slabs was found using the number of slabs installed between 2004 and 2013 (Harley and Jenkins, 2014), the average size of a slab (Kilsaran, 2016) and a cement content of $300 \mathrm{~kg} / \mathrm{m}^{3}$ (Soutsos et al., 2011):

$$
\begin{aligned}
\text { Cement in paving slabs }= & \frac{\text { Area of slabs }(2004-2013)}{\text { Number of years }(=10)} \times \text { Avg. thickness of slab } \\
& \times \text { Avg. cement content of slab }
\end{aligned}
$$


Cement used in railway sleepers was found similarly (assuming a cementitious content of $12 \%$ by mass) from the number of sleepers produced (Anonymous, 2011), and an estimate of the average mass of a sleeper (RailOne, 2018):

$$
\begin{aligned}
\text { Cement in railway sleepers }= & \text { Number of sleepers } \times \text { Avg. mass of sleeper } \\
& \times \text { Avg. cement content of sleeper }
\end{aligned}
$$

Residential The Office for National Statistics publishes house- and flat-building statistics for England (2018a). This was scaled by population to match the UK. The total amount of concrete used in residential applications is known from CEMBUREAU data (CEMBUREAU, 2017); total demand for cement from houses was estimated and it was assumed that the remaining material was used in flats

Houses Annual data on the roof area of new concrete roof tiles for houses is published by the uK Government Department for Business and Strategy (2017). Assuming a mass per $\mathrm{m}^{2}$ of $50 \mathrm{~kg}$ (see e.g. Travis Perkins products) and an average cement content in concrete of $12 \%$ by mass, the demand for cement from concrete roof tiles was calculated:

$$
\begin{aligned}
\text { Cement in concrete roof tiles }= & \text { Area of roof covered } \\
& \times \text { Avg. mass of tile per } \mathrm{m}^{2} \\
& \times \text { Avg. cement content of tile }
\end{aligned}
$$

Today, most houses employ a concrete beam and dense block construction method for ground floors. It was assumed that $90 \%$ of houses use this method, and the rest use a non-cement-based solution. The average floor space of a new house (assumed to be two storeys) is $88 \mathrm{~m}^{2}$ (RIBA, 2011). Using the average floor area and average size of a dense block, we can estimate the number of dense blocks required, and the number of floor beams. This is then multiplied by the number of houses and the average cement content of these applications to find the amount of cement demand 
that they account for.

$$
\begin{aligned}
\text { Cement in concrete floor beams }= & 90 \% \times \text { Number of floor beams per house } \\
& \times \text { Number of houses } \times \text { Mass of floor beam } \\
& \times \text { Avg. cement content }
\end{aligned}
$$

It was assumed that all new houses have double leaf walls made from concrete blocks inside and bricks outside. Blocks were assumed to be used for internal walls. This setup was modelled assuming that internal and external wall areas are equal. Using the average floor area, and assuming a cube-shaped house, the outside wall area and the number of concrete blocks required were estimated. This number aligns well with the number of AAC and lightweight blocks produced, so it was assumed for the rest of the study that all of these types of block are used in housing ${ }^{2}$. Estimating the demand for concrete foundations for houses is difficult $-10 \%$ of all concrete used in houses was assumed to be for this application.

Flats The remaining demand for residential concrete was assumed to be from flats. It was assumed that all flats are built with concrete frames, consistent with findings from interviews with structural designers. Also known are the number of flats produced (Office for National Statistics, 2018a)), while case studies provide values for the amount of concrete used per flat, of approximately $110 \mathrm{~m}^{3}$ (UK, 2017; Tarmac, 2017). This allows us to perform a check: assuming a cementitious content of concrete of around $250 \mathrm{~kg} / \mathrm{m}^{3}$ and 41,000 flats built in the UK in 2014 , this would require $1,130 \mathrm{kt}$ of cementitious material. The mass of cement used in residential applications that is not used in houses is found to be 1,650 kt. The disparity in these

\footnotetext{
${ }^{2}$ This assumption does not affect material efficiency analysis.
} 
figures may be due in part to the assumptions about concrete demand per flat and (more likely) cement content of concrete. Nonetheless, they are of the same order of magnitude, confirming that the approach used is acceptable. The breakdown by application within flats is then calculated using the method detailed in the concrete frame breakdown above.

Non-residential buildings The amount of concrete used in different types of nonresidential sectors - commercial, public, industrial, agriculture and 'other nonresidential uses' - in the eu was also supplied by CEMBUREAU (Rimoldi, 2017).

Public buildings and commercial (offices) The market shares of steel and concrete frames in offices and 'other buildings' uses the values from the Institute (2016). This 'market share' is assumed to correspond to total $\mathrm{m}^{2}$ of floor area. The analysis used to find the breakdown of concrete use in concrete and steel frames above found that 1.44 times more concrete is used per $\mathrm{m}^{2}$ of floor area in a concrete frame than a steel frame. Combining these two estimates, we find that $63.6 \%$ of the concrete used in commercial buildings is in steel frames vs $36.4 \%$ in concrete frames, while for public buildings, $48.3 \%$ of the concrete used is in steel frames, with $51.7 \%$ going to concrete frames. Within these building types, breakdowns of cement use were calculated using the concrete and steel frame breakdowns described above.

Industrial According to Bishop (2001), $6 \%$ of all concrete demand in the UK was for the ground floor of industrial buildings (Bishop, 2001). All dense concrete blocks not used in houses were assumed to be used for industrial applications. The remaining cementitious material was categorised as 'other industrial'.

Agriculture Little information is available pertaining to agricultural uses of concrete. It is likely that there are many different applications, each demanding a small share of cement, so estimating this breakdown is not critical. 
Repairs and maintenance CEMBUREAU provided an estimate of how much concrete is used for repairing and maintaining the existing stock of cement products (CEMBuREau, 2017). The uses of this concrete were not specified further, however a breakdown of repairs in different end-sectors was found using data on spending from the Office for National Statistics and estimates from Woodward and Duffy (2011): $45 \%$ in residential buildings, $45 \%$ in non-residential buildings and $10 \%$ in infrastructure. It was assumed that houses and flats demand an equal amount of cement for repairs, and that all non-residential repairs are for commercial buildings (this is an over-simplification which does not affect the results of the material efficiency analysis).

Precast vs ready-mix concrete frame elements From Part I of the MFA, the total amount of cement used in precast products is known. The following products were assumed to be made from precast concrete: concrete blocks, pipes, railway sleepers, roof tiles and paving slabs. It was assumed that the remainder of precast concrete was used for building frame elements. As the demand for cement from the above applications is known, we can estimate how much cement is used in precast building frame elements (vs in-situ).

Non-concrete applications of cement are: mortar used to bind bricks and blocks; screed used to cover floors and; renders and finishes used to cover wall surfaces. These applications were assumed to have a cement content of $450 \mathrm{~kg} / \mathrm{m}^{3}$ (Limbachiya and Kew 2008).

Mortar Demand for mortar can be calculated by assuming that it is used solely to bind bricks and concrete blocks, for which production statistics are published UK Government Department for Business and Strategy. Assuming that a mortar joint is $10 \mathrm{~mm}$ and that the average dimensions of blocks and bricks are $215 \times 440 \times$ $105 \mathrm{~mm}$ and $215 \times 102.5 \times 65 \mathrm{~mm}$ respectively, the demand for mortar can be calculated. An additional $10 \%$ for waste and poor work was included. Demand 
for mortar from each end-sector was found based on where concrete blocks and bricks are used.

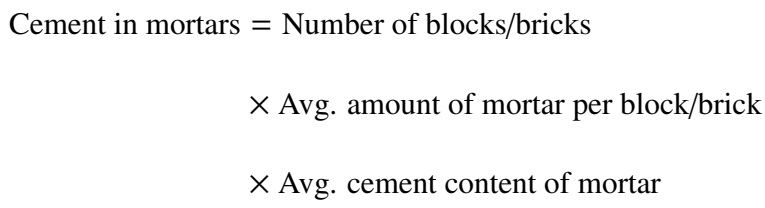

Screed The demand for screeds was estimated assuming it is only used on concrete flooring. Using the average thickness of ground floors and floor slabs from above, and the total mass of cement used for these applications (which has been calculated previously), the total concrete floor area can be estimated. The thickness of a screed varies widely depending on its specific application (some can be structural while others are just used for a smooth finish). An average thickness of $40 \mathrm{~mm}$ was used. This calculation is sensitive to both the assumed thickness of floor slabs and the thickness of screed, and is therefore at best a rough approximation. As with mortars, the demand for screed from building types was broken down assuming it is proportional to the demand for cement in floors.

Renders/finishes Demand for cement in renders and finishes was assumed to be the remainder of non-concrete demand for cementitious material. This was assumed to be proportional to cement demand in offices, public buildings and flats.

\subsection{Material efficiency}

Five technical options for reducing the demand for cement were investigated: 1) posttensioning floor slabs, 2) using more precast frame elements in place of in-situ concrete, 3) reducing the cement content of concrete, 4) using calcined clay and limestone as a cement substitute, and 5) reducing construction waste. These options provide a good coverage of what is possible without changing design practices, which we consider below. This analysis was verified where possible by academics and industry members. Its results were combined with the results of the MFA to produce an estimate of the total 
reduction possible. The carbon reduction enabled by each material efficiency technique was also estimated. Unless otherwise stated, it was assumed that emissions savings are directly proportional to cement savings.

The Mineral Products Association (MPA) estimate that a tonne of the UK's average cementitious material is responsible for $787 \mathrm{kgCO}_{2}$ (Leese and Casey, 2015). Using this statistic, in total uK cementitious material was responsible for approximately $10 \mathrm{MtCO}_{2}$ in 2014. The uK government reported that the cement industry was responsible for just 4.5 $\mathrm{MtCO}_{2}$ (uK Government - Department for Business, Energy and Industrial Strategy, 2016). This implies that considerably different methods were used to calculate average embodied emissions of cement. Part of this disparity is likely to be the in/exclusion of imported material. To ensure that this discrepancy does not impact the results of this study, percentage changes were calculated and the MPA average embodied emissions value was used.

Substitution with calcined clay and limestone Up to $45 \%$ of the clinker in cement can be replaced by a coupled substitution of kaolinite-rich calcined clay (30\%) and limestone (15\%) (Scrivener, 2014; Zhou et al., 2017), producing concretes that are at least as strong as mixes using pure CEM I (Antoni et al., 2012; Cancio Díaz et al., 2017). Replacement by a further $15 \%$ (to $60 \%$ in total) will produce concrete that is $93 \%$ as strong as Portland cement (Antoni et al., 2012). Global penetration could replace cement by 10-20\% (Scrivener, 2018). In this work, we assumed that the cement in all concrete applications could be substituted with London clay (Zhou et al., 2017) and limestone by $45 \%$. Approximately half of all mortars are used for bricks, and are therefore unlikely to bear high loads meaning these mortars can be replaced by $60 \%$ with calcined clay and limestone. The remaining clinker in mortars can then be replaced by $45 \%$. Finishings and renders do not require structural strength and can replaced by $60 \%$ with clay and limestone. Expert estimation suggests that at least a third of all screeds are 
structural. A value of $40 \%$ was assigned for this proportion. This cement can be replaced by up to $45 \%$ without risking harming its properties. Clinker in the remaining $60 \%$ of screeds can be substituted $60 \%$. The key limiting factor is local availability of raw material: in the UK, supplies are available (British Geological Survey, 2009; Zhou et al., 2017). Calcined London clay embodies only $70 \mathrm{kgCO}_{2} /$ tonne (Zhou et al., 2017), while limestone has an emissions intensity of 30-90 $\mathrm{kgCO}_{2} /$ tonne (a value of $60 \mathrm{kgCO}_{2} /$ tonne was used) (Leese and Casey, 2015; Hammond and Jones, 2008).

Reducing the binder intensity in concrete Designing mixes for a target strength can be achieved for a wide range of cement cement content. For example, Obla et al. (2017) observe little consistency in the relationship between cementitious content (in the range $350 \mathrm{~kg} / \mathrm{m}^{3}-415 \mathrm{~kg} / \mathrm{m}^{3}$ ) and compressive strength, and the results suggest that cementitious content could be reduced by $30 \%$ without significant loss of strength (Obla et al., 2017). It is likely possible to allow lower binder intensity than the curent code prescription: Wassermann et al. (2009) find that concrete 28-day strength does not vary with cement content (between $160-200 \mathrm{~kg} / \mathrm{m}^{3}$ ), implying that $200 \mathrm{~kg} / \mathrm{m}^{3}$ cement concretes could reduce their binder contents by $20 \%$ without loss of strength properties (Wassermann et al., 2009). This study also found that various other durability indicators are unaffected. For the purposes of this analysis, a $15 \%$ possible reduction in cement content was used, for all applications in concrete, as well as structural screeds.

Precast concrete frames Precast elements are made in a more controlled environment with greater precision than in-situ concrete, so designers can have greater confidence in thinner parts that use material more efficiently. More complex parts such as 'voided' slabs that are significantly lighter and use less material can also be produced. Data on the possible savings are sparse, however. The Bison Hollowcore solution is claimed to save up to $23 \%$ of material (Bison Precast Ltd., 
2007). A conservative estimate of $15 \%$ concrete savings, that could be applied to floors, beams and columns, was assumed. This saving can only be applied to non-precast structural elements, which constitute $67 \%$ of current frame elements as found above. Emissions factors of precast and in-situ concretes are not reliable. Bison claim that emissions savings are the same as material savings, implying the cement content in their concrete is the same as the average in-situ mix (Bison Precast Ltd. (2007)). Hammond and Jones (2008) estimate that precast concrete is $37 \%$ more emitting than in-situ, while a case study performed by Mao et al. (2013) found precast concrete to result in $10 \%$ less carbon emissions in two residential case-studies. Certainly, the carbon embodied by precast elements depends on many variables: the distance from factory to site and the cementitious material content, for example. In this investigation, it was assumed that precast and ready-mix concretes embody the same level of carbon. In the UK, less FA and GGBFS are added to precast concrete than in-situ concrete because of their effect on its setting time. A compromise between speed of production and embodied carbon must be found in order to improve sustainability - this investigation assumes that this is possible.

Post-tensioning concrete floor slabs This is the stressing of the steel reinforcement (rebar) in concrete floor slabs, before external loads are applied, to increase the proportion of concrete that is in compression. This allows thinner parts that use less concrete and steel. A case study by vsL found that post-tensioning saves $23 \%$ on concrete and $48 \%$ on steel, resulting in a lowering of emissions by $37 \%$ (Post Tensioning Association). A study by Miller et al. (2013) found that concrete demand was reduced by $36.9 \%$ and steel demand by $43.4 \%$. There are also beneficial knock-on effects of post-tensioning floors slabs. Because they are thinner and lighter, other structural elements can also be smaller and use less cement. López-Mesa et al. (2009) find that foundations can be reduced by 
$14.3 \%$, columns by $25.0 \%$ and beams by $37.6 \%$ (López-Mesa et al., 2009). Posttensioning cannot be applied to all flooring systems; it is economical for spans above roughly 6 m (Post Tensioning Association; Mineral Products Association, 2015b). Residential spans (in flats) generally are shorter, so it was assumed that post-tensioning would not be used in residential applications. Outside of these applications, post-tensioning is not commonly used (as confirmed by multiple interviewees); it was assumed that a $20 \%$ saving could be applied to $95 \%$ of (non-residential) floor slabs.

Reducing construction waste The uK construction industry contributes nearly half of all landfill waste (Ajayi et al., 2016); the most efficient countries waste about $3 \%$ of all concrete produced (Kazaz et al., 2015). It was assumed that there is negligible waste in precast plants, so savings here can only be applied to ready-mix concrete.

Reducing over-design in construction There are many ways this over-specification of concrete parts is brought about: the desire to use the same formwork, unnecessary corrosion protection for indoor parts, using a concrete mix that is stronger than it needs to be, or using repeated elements to reduce labour costs, for instance. The extent to which each results in excessive demand for cement will vary between designers, buildings and parts. Unlike for steel, no data on the material overspecification of cement's products can be found in the literature. Therefore, we used the same headline overspecification as for steel, as it was shown to be driven by the engineer's decision to favour utilisation ratios for members of $80 \%$ of the code allowance (Moynihan and Allwood, 2014; Dunant et al., 2017). In interviews, we found that concrete designers are similarly cautious, leading likely to a similar material under-utilisation. We have therefore assumed that the cement use in structural elements could be reduced by $20 \%$ by changing the way elements are specified. 
There are many more ways of improving the efficiency with which we use cement. Using bespoke parts, perhaps with variable depth, or at the least using a wider variation of elements whose material demands more closely reflect the strength needed, would be considered material efficiency techniques. These could be considered in future works, but are likely to only represent marginal savings.

\subsection{Combining the map of cement flow and material efficiency improvements}

The map of cementitious material flow, and information regarding material efficiency techniques - which applications they can be applied to, how much material they save and what the associated emissions reductions would be per unit of cement reduction can be combined to estimate total demand and emissions reductions.

There are caveats to this analysis; applying three material efficiency measures that independently reduce cement demand from an application by $30 \%$ would not result in a $90 \%$ reduction. The reduction is cumulative according to Equation 11 where $R_{i, a}$ is the $\%$ saving of demand for application a due to efficiency measure $i$.

$$
\text { Total reduction for application } a(\%)=100-\prod_{i=1}^{n} 100-R_{i, a}
$$

In this analysis, the order in which material efficiency measures are implemented affects the total reduction that can be attributed to each measure (it doesn't affect the combined reduction from all measures, however). This order was chosen by prioritising by the state-of-readiness of each measure. Post-tensioned slabs and precast frame elements are already in use. Increasing the production of precast elements would require the output of the industry to roughly triple, which is more challenging than using a different design and construction method for floor slabs only through post-tensioning. Post-tensioning was therefore 'implemented' first. Reducing the cement content of concrete and using calcined clay and limestone as cementitious substitutes were considered the next closest to being implementable. Codes and standards do not exist for either technology, and research into their efficacy and applicability is not complete; they were considered fairly 
even in this sense. Reducing the cement content of concrete is more beneficial in terms of emissions savings (per unit of cement demand reduction), and it is therefore logical to prioritise this action over using replacement materials.

\subsection{Interviews with industry}

To verify the methods used and results obtained in this research, structural designers from three leading firms (Ramboll uk Ltd., Expedition Engineering, and Price \& Myers) were interviewed. The interviews lasted 30-40 minute cand interviewees were asked direct questions about:

- the method used here for calculating the breakdown of cement demand in steeland concrete-framed buildings (all interviewees were structural designers of buildings so their areas of expertise did not encompass other topics like infrastructural uses of cement),

- material efficiency techniques that could be applied to ground floors, and their feasibility,

- material efficiency techniques that could be applied to floor slabs, and their feasibility,

- the possibility of using more FA and GGBFS in concrete,

- precast vs ready-mix concrete — materials and emissions savings and why designers/contractors choose one or the other currently, and

- repairs and maintenance — what is being repaired and how could this demand be reduced.

Interviewees were then asked about their own general ideas pertaining to cement and concrete use in the construction industry: what contributes to inefficiency and what the limitations of trying to change design techniques might be, for example. All the material deruction techniques proposed in this paper have been discussed and validated as possible by all the interviewees. 


\section{Results}

The results of the MFA and the investigation into material efficiency in the cement industry are presented here.

3.1. MFA

Figure 3 (top) shows the uK use 10,540 kt of raw material to make 7,419 kt of clinker. Approximately 2,600 kt of low-carbon FA and GGBFs and $1000 \mathrm{kt}$ of other low-carbon cementitious materials (accounting for $20 \%$ of total cementitious material) and 1,935 kt of imports are added to make up the 13,030 kt of cement used in the UK. Figure 3 (bottom) shows a breakdown of cement into its end-use applications. It shows that $83 \%$ of all cement is used in buildings, $13 \%$ in infrastructure and $4 \%$ for other miscellaneous uses. $80 \%$ cement ends up in concrete, $15 \%$ in mortars and the remainder as other miscellaneous forms like as a powder for soil stabilisation.

The demand for cement from more generalised application types is shown in Figure 4. Building frame elements, at 2,922 kt, account for $22 \%$ of all cement demand. Repairs and maintenance account for 1,820 kt (14\%). Industrial and transport applications and concrete blocks each consume approximately 1,000 kt (7.5\%) of cement, and building foundations contribute a further $5 \%$. Of the non-concrete applications, screeds consume the most cement, followed by renders then mortars.

Uncertainties for Part I of the MFA are shown in Figure 5. These values are generally less than $20 \%$. The uncertainty in the mass of GGBFs, quicklime and limestone fines being added to precast concrete is $30 \%$, while the amount of GGBFs being added to ready-mix concrete is more uncertain, at $50 \%$.

\subsection{Material efficiency}

Total cement demand in the uK can be reduced by up to $56 \%$. Total carbon emissions from cement demand in the uK could be reduced by $44 \%$, as shown by Figure 6 when applying the material efficiency techniques. Figure 7 illustrates how much the demand from each of cement's applications can be reduced, ranked by application. Floor slabs 

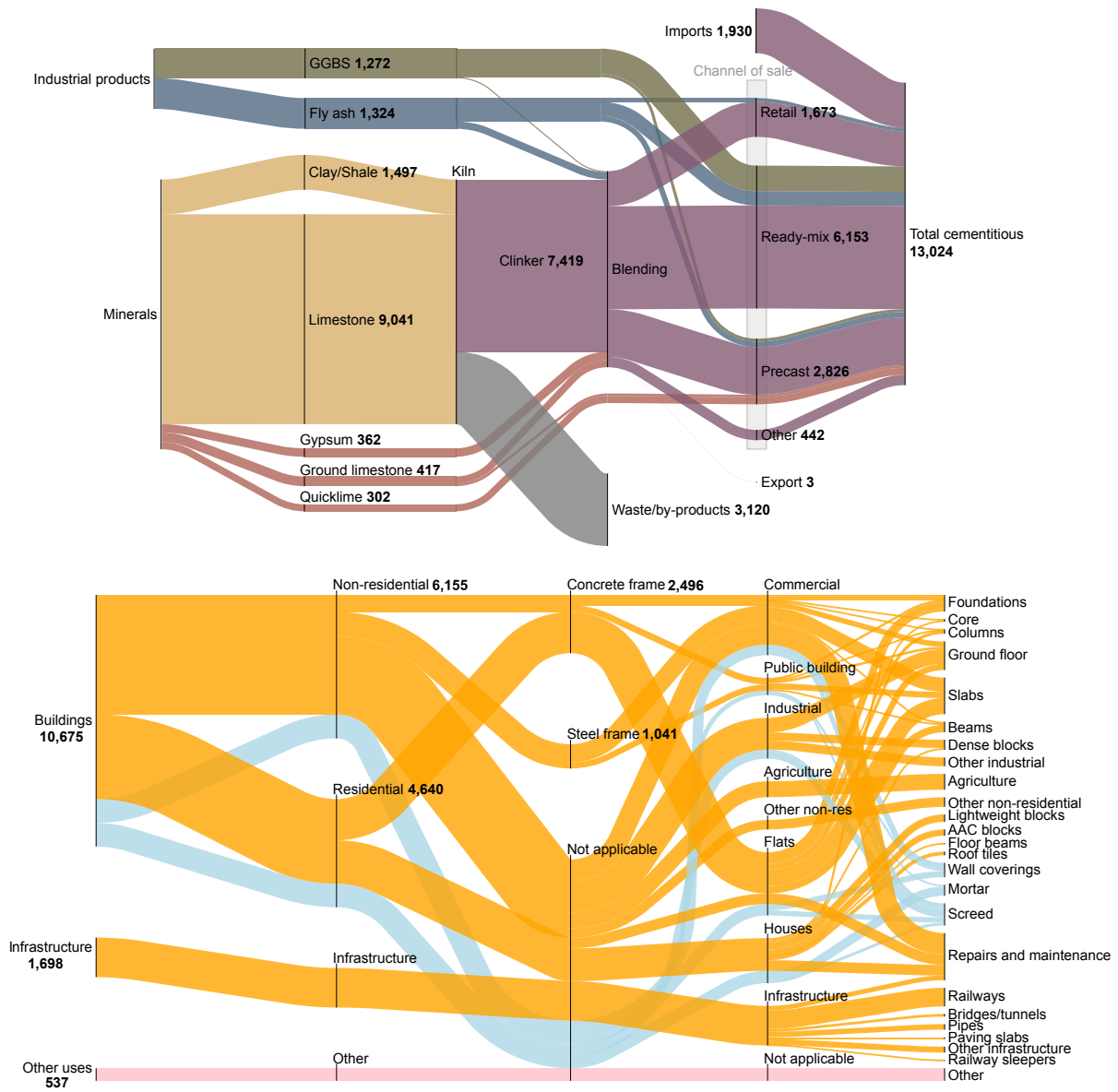

Figure 3: Numbers on the figure represent mass flow in kt. The width of the links represents mass flow while colours represent materials. (top) The vertical 'slices' represent salient processes in the production of cement. Imports mean the total amount of cementitious material in the uK's cement industry is $13,030 \mathrm{kt}$. The sale-types of the imported cement are were not determined in the MFA. (bottom) Slices represent applications of cement. Orange marks concrete, light blue mortars and pink powders used as soil stabilisation and other miscellaneous applications. The vertical slices represent: the industry (buildings, infrastructure, other), the construction sector (non-residential etc.), the type of structural frame (if applicable), the construction type (commercial buildings, public buildings etc.), and the final slice shows the applications themselves. Diagram produced using floWeaver (Lupton and Allwood, 2017; Lupton, 2018-) 


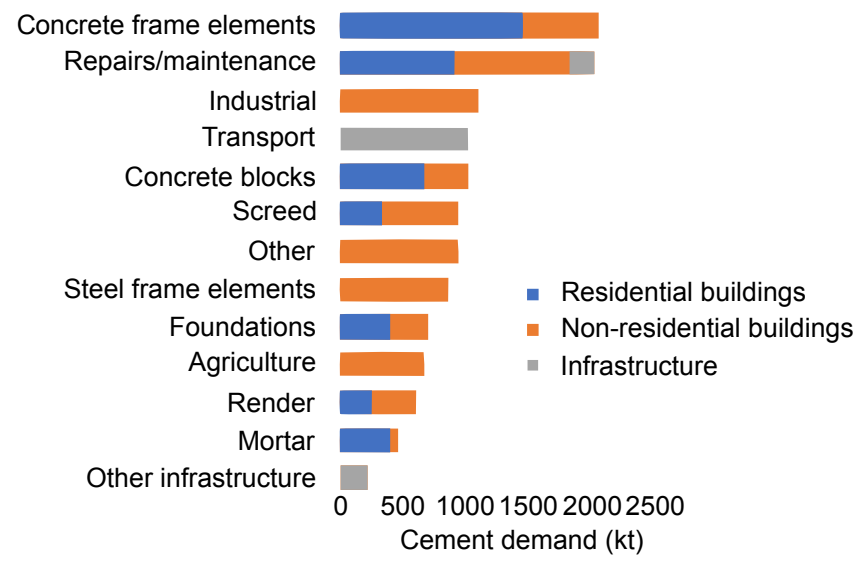

Figure 4: Cement demand by application type in the uK.

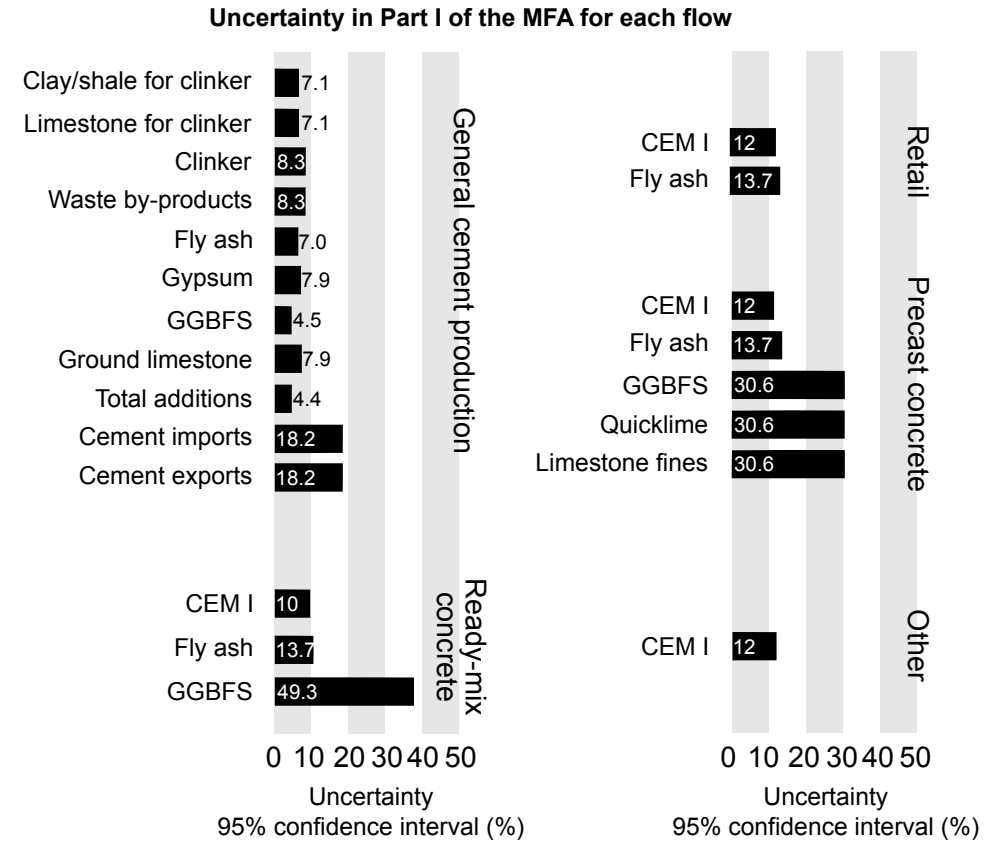

Figure 5: The results of the uncertainty analysis for Part I of the MFA. The true mass flow is expected to fall within twice the uncertainty shown of the mean.

646

and ground floors should be prioritised as they account for the highest shares of demand.

Repairs and maintenance, because of their large contribution to overall demand, can be reduced by the second most in absolute terms. To achieve the reduction, a number of means are available. Using calcined clay and limestone has large potential to reduce 
cement demand: $13 \%-40 \%$ reductions are possible, depending on clay quality is used as a substitute for cement. Reducing the binder content in concrete can reduce demand further by $10 \%$.

To produce the figures, we have multiplied the flow corresponding to the end application by the applicable efficiencies. As the result depend on the order of application, we have applied the material efficiency techniques in decreasing order of potential reduction, with the exception of optimising construction ('Reducing over-design in construction') which was applied last, as it would require a cultural change. Figure 7 and Figure 6 thus display the same data, agglomerated differently.

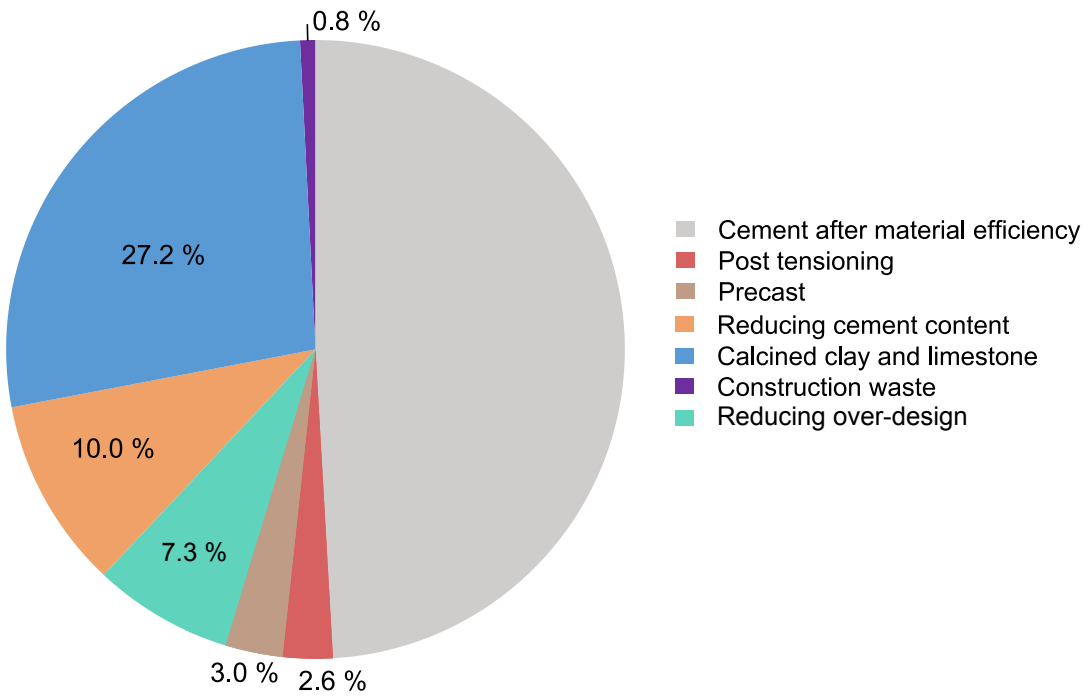

Figure 6: Pie charts showing the carbon emissions due to uk demand for cement in 2014, broken down into that which is necessary and that which could be reduced by each of six material efficiency techniques, as well as reducing over-design in construction.

All the methods presented above are independent of the design practice of the construction industry. We have thus decided to apply the final material efficiency technique, reducing overdesign, last. The savings from optimised design can then be found by assuming a $20 \%$ saving to be applicable accross the board in concrete structural elements in buildings: floor slabs, ground floors, foundations, beams, screeds, 
columns and floor beams. This brings the headline figure of potential carbon abatement to $51.3 \%$.

\section{Discussion}

\subsection{Reliability of the analysis}

The uncertainty analysis performed in Part I of the MFA suggests that mass flow values for material inputs and cement's 'channel of sale' are reliable. Although quantitative analysis of uncertainty in Part II was not performed, qualitative comments can be made. The starting-point of all calculations was the CEMBUREAU statistics for end-sector uses of concrete for the UK from 2007-2009 (CEMBUREAU, 2017), which were checked against industry spending breakdowns (Office for National Statistics, 2015). Their close agreement affirms that these data are a sound basis from which to continue estimation. The uncertainty associated with the subsequent estimates for demand from individual products will vary widely; some applications were calculated from direct data and so can be stated with a reasonable degree of confidence. Other applications were calculated through more convoluted methods, using several assumptions and case studies that may not be applicable (see steel- and concrete-framed elements and foundations, for example).

Two important simplifications may affect the results: that all products use cement with the same composition (which was assessed as reasonable in interviews), and that all concretes have the same cement content (which is known to be true on average). Furthermore, simplifications were made when estimating how much a material efficiency technique could reduce cement demand from an application. Post-tensioned slabs and precast concrete elements were assumed to have the same emissions factors as the UK average cement, which may not be the case. The results here are also dependent on the order of 'implementation' of the material efficiency techniques, although sensitivity is not particularly high. A summary of the uncertainty of the various techniques can be found in Table 2. 


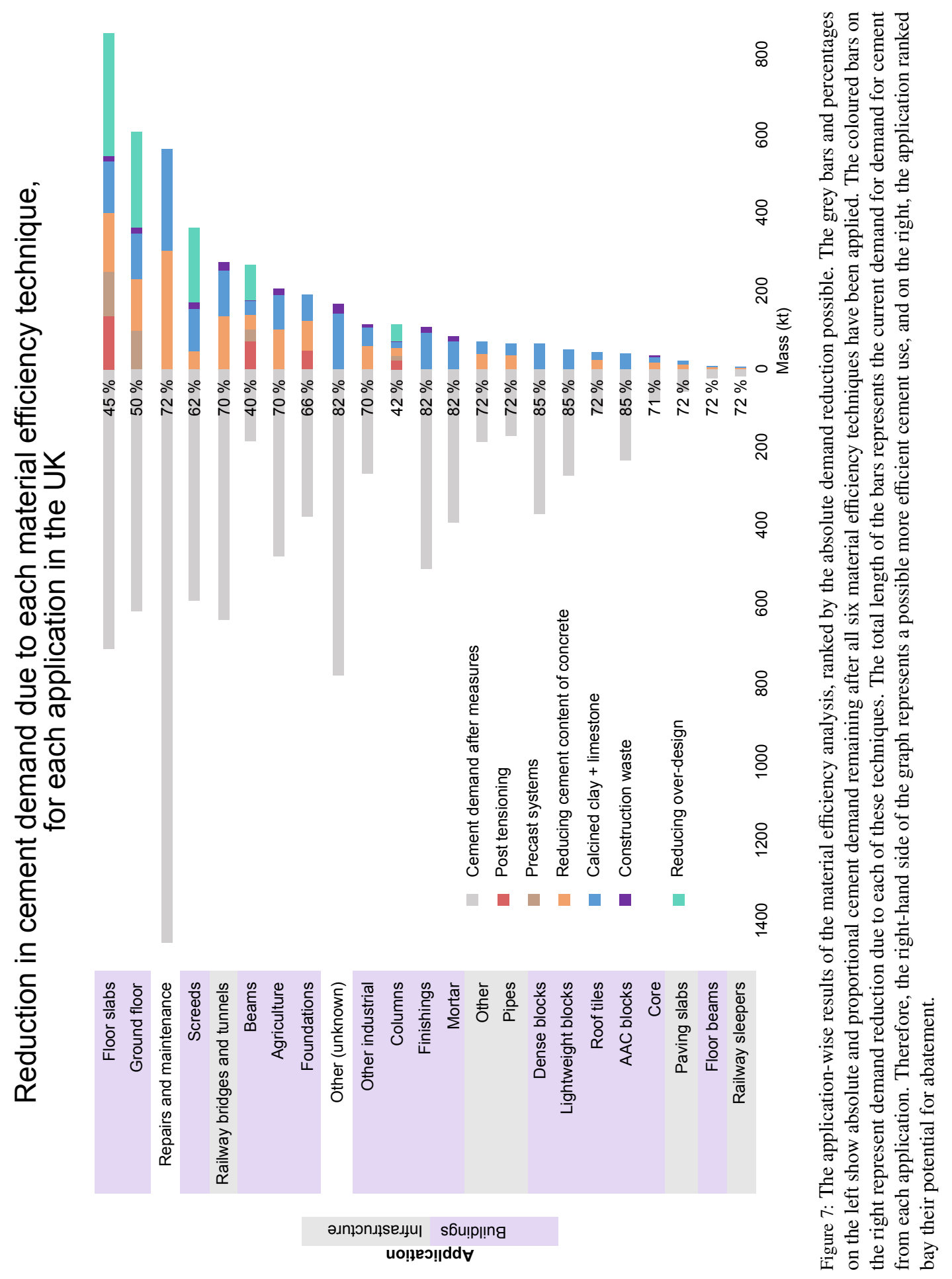


Table 2: Range of efficiency associated with the various techniques due to uncertainties.

\begin{tabular}{rlll}
\hline Technique & Applicability & Benefit & Total \\
\hline Post-tensioning & $95-100 \%$ & $14-36 \%$ & $13.3-36 \%$ \\
Precast Elements & $0-67 \%$ & $15-23 \%$ & $0-15.4 \%$ \\
Cement Content & $50-90 \%$ & $0-30 \%$ & $0-27 \%$ \\
Calcined Clay & $80-100 \%$ & $51-52 \%$ & $40.8-52 \%$ \\
Construction waste & $44-50 \%$ & $0-3 \%$ & $0-1.5 \%$ \\
\hline
\end{tabular}

The material flow analysis was performed on a single year without consideration of the possible changes to overall demand or demand from individual applications over time. Demand in the uK is unlikely to change significantly compared to countries which use more cement or to developing countries whose demand will increase in the coming years. The results of this work suggest that material efficiency techniques related to composition can have more of an impact than those related to the design of products. However this is because several design techniques were not considered, such as reducing the over-specification of concrete or designing for re-use. These were not included because material savings were difficult to quantify, but this doesn't mean that they cannot be important. The map of cement flow produced in the MFA provides data with which the potential of these measures can be assessed.

\subsection{Recommendations}

Buildings account for a dominant share of the demand for cement. A technique to improve the efficiency of a concrete application would need to target only a few institutions (designers, contractors etc.) To encourage more efficient use of cement in mortars would require changing the practices of many small builders, with wider set of applications, which would be more difficult. Repairs and maintenance, mostly of buildings, account for the largest demand of any single 'application'. More detailed knowledge of what these repairs are needed for is essential to reduce this demand. Nonetheless, why is there such a large need for repairs — is it poor initial design, retro-fitting, or just unavoidable degradation? would attempting to reduce this demand 
through more durable products just increase the cement needed initially, resulting in an increase?

Demand for cement in undetermined industrial and agricultural applications is high. It is likely that agricultural applications involve in-situ concrete for flooring of farms. Material efficiency options are therefore limited to changing the composition of cement and concrete. Design efficiency options may have more of an effect on industrial applications, like concrete warehouse frames. Concrete blocks are ubiquitous, and perhaps difficult to target for efficiency improvements because there are many small manufacturers, requiring legislating their composition. Other significant sources of cement demand include screeds, foundations, and 'other' uses. As with other mortars, screeds are difficult to improve, other than through composition change. Foundations have not been assessed for specific material efficiency improvements in this work.

Of the material efficiency options studied, changing cement and concrete's compositions may have greater potential to reduce carbon emissions than any single design or structural option. Substituting clinker in cement with calcined clay and limestone can reduce UK cement demand by between $13-40 \%$ depending on the clay used, with resultant emissions reductions of 10-27\%. Technological research into the use of calcined clay for concrete is fairly mature. In addition to reducing concrete's carbon emissions, this technology can reduce costs, be produced in existing cement plants, and would not require major changes to concrete technology, and has no durability downsides (Scrivener, 2014). If these binders become widely available, uptake will depend largely, as with the use of current additions FA and GGBFs, on early-age strength development, as well as managing the workability of the new binders (Antoni et al., 2012). Nonetheless, changes to the current concrete standards are still needed for calcined clay and limestone to become a viable material efficiency technique. Further, the availability of these materials is the primary limiting factor for uptake in the uK in the long term, and accurate determination of the emissions reductions possible through this strategy is 
critical to its prioritisation as an efficiency technique.

Reducing the binder content of concrete has the potential to reduce demand and carbon emissions by $10 \%$. As with calcined clay and limestone replacement, there will need to be a change of concrete standards once the technology is proven. Concrete technologists and specifiers of concrete mixes will need to be educated on this strategy and encouraged to use it for all applications; this will be difficult because human tendency is to overspecify requirements and 'stay with what they know' (as repeated by interviewees). Cement manufacturers would likely resist this step because it could threaten revenues.

Optimising construction designs would need a cultural change in the way buildings are engineered. Nonetheless, this can represent a $7 \%$ saving in emissions, if all other measures are applied. Done on its own, it would represent a $20 \%$ savings. Specific technologies have less potential. Using only precast elements could reduce carbon emissions by $3 \%$. This strategy would require a shift in the entire construction industry, as well as a tripling in the capacity of precast manufacturers. Acknowledged in the methodology section, and confirmed by an interviewee, the actual cement savings from precast concrete are very hard to predict because there are many variables involved. According to several of the interviewees, the choice of precast vs poured in-situ concrete is mostly determined by logistical variables: costs, site access and crane time, for example. Precast is generally used when it is cheaper, determined by the above reasons. Given that possible benefits are estimated to be low and highly uncertain, pursuing this option should not be of the highest priority in the UK.

Post-tensioning (but equally other floor slab material efficiency techniques for which it acts as a surrogate) would only contribute a $2.6 \%$ reduction in cement demand and emissions. This reduction in emissions is not guaranteed, because as stated by one interviewee, some post-tensioning systems use higher cement contents; in construction, post-tensioning is done to save on thickness of parts and not for environmental reasons. 
Another interviewee disagreed with this, however, arguing that the major design concerns associated with post-tensioning are unrelated to cement content and so there is no reason for them to use above average. It is certainly feasible to increase the use of posttensioning in building design above today's level. However, a $100 \%$ increase is not feasible, and so post-tensioning should not be pursued as a critical material efficiency technique.

\section{Conclusions}

An unprecendented map of the flow of cementitious material has been developed for the UK in 2014, using published data on building materials and various methods of estimation. $83 \%$ of cement is used in buildings, with the remainder (13\%) mostly being used for infrastructure. Building frame elements account for the highest share of demand, followed by repairs and maintenance, industrial and agricultural uses, and concrete blocks. The first half of this map, Part I of a material flow analysis, carries a relatively small degree of uncertainty. Using a method developed by Laner et al. (2015), the uncertainties in material use and cement demand were generally estimated to be $\pm 5-30 \%$. Part II of this material flow analysis evaluated the demand for cement from 25 different applications.

The results of this analysis show that in terms of material demand reduction, substituting cement with calcined clay and limestone has by far the greatest potential, followed by reducing the cement content of concrete. In total, the six technical measures investigated could reduce the uK's cement emissons by $44 \%$. Further, optimising designs can bring the abatement potential to $51 \%$. Importantly for policy, none of these options would require changes in consumer habits, and only minimal changes in the way buildings are designed. Rather, they need production at scale of novel but available and economically viable scm, as well as designers to have better incentives to optimise the design of buildings. 


\section{Acknowledgements}

We would like to warmly thank the engineers who answered our questions for their invaluable help in this analysis and their expertise.

This work was supported byePSRc Material demand reduction: NMZL/112, RG82144, EPSRC reference: EP/N02351X/1.

\section{References}

Abdelrahman, A.A., 2017. Applications of sustainable post-tensioned concrete slabs. Innovative Infrastructure Solutions 2, 42. URL: https : //link.springer.com/ article/10.1007/s41062-017-0075-6, doi:10.1007/s41062-017-0075-6.

Ajayi, S.O., Oyedele, L.O., Akinade, O.O., Bilal, M., Owolabi, H.A., Alaka, H.A., Kadiri, K.O., 2016. Reducing waste to landfill: A need for cultural change in the UK construction industry. Journal of Building Engineering 5, 185-193. URL: http://linkinghub.elsevier.com/retrieve/pii/ S2352710215300590, doi:10.1016/j · jobe.2015.12.007.

Allwood, J.M., Ashby, M.F., Gutowski, T.G., Worrell, E., 2011. Material efficiency: A white paper. Resources, Conservation and Recycling 55, 362-381. URL: http://www.sciencedirect.com/science/article/pii/ S0921344910002405, doi:10.1016/j.resconrec.2010.11.002.

Anonymous, 2011. Mandate AO/008: Network Rail Materials Costs Benchmarking Study. Technical Report. Network Rail and the Office of Rail Regulation. URL: http://orr.gov.uk/__data/assets/pdf_file/0003/10011/ benchmarking_2011_arup_report.pdf.

Antoni, M., Rossen, J., Martirena, F., Scrivener, K., 2012. Cement substitution by a combination of metakaolin and limestone. Cement and Concrete Research 42, 
1579-1589. URL: http://www.sciencedirect.com/science/article/pii/ S0008884612002074, doi:10.1016/j.cemconres. 2012.09.006.

Bishop, J., 2001. The early age behaviour of concrete industrial ground floor slabs. Ph.D. thesis. Loughborough University. URL: https://dspace.lboro.ac.uk/ dspace-jspui/handle/2134/6786.

Bison Precast Ltd., 2007. Precast Concrete Flooring. Technical Report. URL: http://www.bison.co.uk/pdf/hcf.pdf.

British Geological Survey, 2009. Kaolin. Technical Report. URL: http://www. bgs . ac.uk/.

British Geological Survey, 2014. Mineral Planning Factsheet - Cement. Technical Report. URL: http://www.bgs.ac.uk/mineralsUK/planning/ mineralPlanningFactsheets.html.

British Precast - Mineral Products Association, 2015. Sustainability Matters 2015. Technical Report. Mineral Products Association. URL: https://www.britishprecast.org/Precast/media/BPMediaLibrary/ Publications/Pubs.

Broadhead, E., 2017. Mapping the Resource Flow of Cement. Fourth Year Project. CUED.

Brunner, P.H., Rechberger, H., 2003. Practical Handbook of Material Flow Analysis. 1 edition ed., CRC Press, Boca Raton, FL.

Building and Construction Authority, 2012. Sustainable Construction - A Guide on Concrete Usage Index. Technical Report. Building and Construction Authority. Singapore. URL: https://www.bca.gov.sg/SustainableConstruction/ others/sc_cui_final.pdf. 
UK Government Department for Business, E., Strategy, I., 2017. Monthly Statistics of Building Materials and Components - June 2017. Technical Report. uK Government. URL: https://www.gov.uk/government/uploads/system/uploads/ attachment_data/file/624737/17-cs7_-__Construction_Building_ Materials_-_Bulletin_June_2017.pdf.

Cancio Díaz, Y., Sánchez Berriel, S., Heierli, U., Favier, A.R., Sánchez Machado, I.R., Scrivener, K.L., Martirena Hernández, J.F., Habert, G., $2017 . \quad$ Limestone calcined clay cement as a low-carbon solution to meet expanding cement demand in emerging economies. Development Engineering 2, 8291. URL: http://www.sciencedirect.com/science/article/pii/ S2352728516300240, doi:10.1016/j. deveng.2017.06.001.

Cao, Z., Shen, L., Liu, L., Zhao, J., Zhong, S., Kong, H., Sun, Y., 2017a. Estimating the in-use cement stock in China: 1920-2013. Resources, Conservation and Recycling 122, 21-31. doi:10.1016/j.resconrec. 2017.01.021.

Cao, Z., Shen, L., Lovik, A.N., Müller, D.B., Liu, G., 2017b. Elaborating the history of our cementing societies: an in-use stock perspective. Environmental Science \& Technology 51, 11468-11475.

CBA, 2008. Aggregate Concrete Blocks - A Guide to Selection \& Specification. Technical Report. Concrete Block Association. URL: http://www . thakeham.co. uk/images/upload/docum/Block\%20Selector.pdf.

cembureau, 2017. Cement consumption, by end uses of cement. Obtained through private communication.

Coelho, E., Candeias, P., Anamateros, G., Zaharia, R., Taucer, F., Pinto, A.V., 2004. Assessment of the seismic behaviour of RC flat slab building structures, in: Proceedings of 13th world conference on earthquake engineering. Vancouver (BC): IAEE. 
Damineli, B., John, V., 2012. Developing Low $\mathrm{CO}_{2}$ concretes: Is clinker replacement sufficient? The need of cement use efficiency improvement. Key Engineering Materials 517, 342-351. doi:10.4028/www.scientific.net/KEM.517. 342.

Department for Business, Energy \& Industrial Strategy, Mineral Products Association, 2017. Industrial Decarbonisation and Energy Efficiency Roadmap. Technical Report. URL: https://www.gov.uk/government/publications/ industrial-decarbonisation-and-energy-efficiency-roadmaps-to-2050.

Dewar, J., 2003. Concrete mix design, in: Advanced Concrete Technology, pp. 3-40. doi:10.1016/B978-075065686-3/50287-1.

Dunant, C., Drewniok, M., Eleftheriadis, S., Cullen, J., Allwood, J., 2017. Regularity and optimisation practice in steel structural frames in real design cases. Resources, Conservation and Recycling .

EN BS 197-1, 2000. Cement-Part 1: Composition, specifications and conformity criteria for common cements. Standard. British Standards Institution.

European Ready Mixed Concrete Organization, 2017. Ready-Mixed Concrete Industry Statistics - Year 2015. Technical Report. URL: http://www. ermco.eu/ document/ermco-statistics-2015-final-pdf/.

Eyre, J.R., 2006. Membrane action in ground-bearing concrete slabs. Proceedings of the Institution of Civil Engineers - Structures and Buildings 159, 153163. URL: https://www.icevirtuallibrary.com/doi/abs/10.1680/stbu. 2006.159.3.153, doi:10.1680/stbu.2006.159.3.153.

Fernández, J., 2007. Resource consumption of new urban construction in China. Journal of Industrial Ecology 11, 99-115. doi:10.1162/jie.2007.1199.

Formichi, P., 2008. Eurocode 1 - Actions on Building Structures. URL: http:// eurocodes.jrc.ec.europa.eu/doc/Moscow08/Moscow08_9_Formichi.pdf. 
Gao, T., Shen, L., Shen, M., Liu, L., Chen, F., 2016. Analysis of material flow and consumption in cement production process. Journal of Cleaner Production 112, 553-565. URL: http://www.sciencedirect.com/science/article/pii/ S0959652615011440, doi:10.1016/j.jclepro.2015.08.054.

Government of the United Kingdom, 2008. Climate Change Act.

Griffin, P., Hammond, G., Norman, J., 2014. Prospects for emissions reduction in the UK cement sector. Proceedings of Institution of Civil Engineers: Energy 167, 152-161. doi:10.1680/ener.14.00007.

Hammond, G., Jones, C., 2008. Embodied energy and carbon in construction materials. Proceedings of Institution of Civil Engineers: Energy 161, 87-98. doi:10.1680/ ener.2008.161.2.87.

Harley, M., Jenkins, C., 2014. Research to ascertain the proportion of block paving sales in England that are permeable. Technical Report. Adaptation Sub-Committee, Committee on Climate Change. URL: https://www.theccc.org.uk/wp-content/ uploads/2014/07/7-ASC-paving-survey-report_for-publication.pdf.

Van den Heede, P., De Belie, N., 2012. Environmental impact and life cycle assessment (LCA) of traditional and 'green' concretes: Literature review and theoretical calculations. Cement and Concrete Composites 34, 431-442. URL: http://www.sciencedirect.com/science/article/pii/ S0958946512000054, doi:10.1016/j. cemconcomp.2012.01.004.

Institute, S.C., 2016. Cost of structural steelwork. URL: https://www. steelconstruction.info/Cost_of_structural_steelwork.

International Energy Agency, 2018. Technology Roadmap - Low-Carbon Transition in the Cement Industry. Technical Report. URL: https://webstore.iea.org/ technology-roadmap-low-carbon-transition-in-the-cement-industry. 
International Energy Agency, The World Business Council for Sustainable Development, 2009. Cement Roadmap. Technical Report. URL: \{https://www.iea.org/publications/freepublications/publication/ Cement_Roadmap_Foldout_WEB.pdf\}.

Kapur, A., Keoleian, G., Kendall, A., Kesler, S., 2008. Dynamic modeling of in-use cement stocks in the United States. Journal of Industrial Ecology 12, 539-556+4. doi:10.1111/j.1530-9290.2008.00055.x.

Kazaz, A., Ulubeyli, S., Er, B., Arslan, V., Arslan, A., Atici, M., 2015. Fresh Readymixed Concrete Waste in Construction Projects: A Planning Approach. Procedia Engineering 123, 268-275. URL: http://www.sciencedirect.com/science/ article/pii/S1877705815031896, doi:10.1016/j .proeng.2015.10.088.

Kilsaran, 2016. Specification \& Installation Guidance. Technical Report. URL: http://www.kilsaraninternational.co.uk/uploaded/ 53199bbbe60f 19.58440664.pdf.

Laner, D., Feketitsch, J., Rechberger, H., Fellner, J., 2015. A Novel Approach to Characterize Data Uncertainty in Material Flow Analysis and its Application to Plastics Flows in Austria. Journal of Industrial Ecology 20, 1050-1063. URL: http: //onlinelibrary.wiley.com/doi/10.1111/jiec.12326/abstract, doi:10. $1111 /$ jiec. 12326.

Leese, R., Casey, D., 2015. Embodied $\mathrm{CO}_{2} e$ of UK cement, additions and cementitious material. Technical Report. Mineral Products Association. URL: http://cement . mineralproducts.org/documents/Factsheet_18.pdf.

Li, J., Tharakan, P., Macdonald, D., Liang, X., 2013. Technological, economic and financial prospects of carbon dioxide capture in the cement industry. Energy Policy 61, 1377-1387. URL: http://www.sciencedirect.com/science/article/ pii/S0301421513004370, doi:10.1016/j.enpol.2013.05.082. 
Limbachiya, M.C., Kew, H.Y., 2008. Excellence in Concrete Construction through Innovation: Proceedings of the conference held at the Kingston University, United Kingdom, 9 - 10 September 2008. CRC Press. Google-Books-ID: FOZTNIDN3cYC.

Low, M.S., 2005. Material flow analysis of concrete in the United States. Thesis. Massachusetts Institute of Technology. URL: http://dspace.mit.edu/handle/ $1721.1 / 33030$

Lupton, R.C., 2018-. floWeaver. https://github.com/ricklupton/floweaver. doi:https ://doi.org/10.5281/zenodo. 596249.

Lupton, R.C., Allwood, J.M., 2017. Hybrid Sankey diagrams: Visual analysis of multidimensional data for understanding resource use. Resources, Conservatin \& Recycling 124. URL: https://www.repository.cam.ac.uk/handle/1810/ 265367, doi:10.17863/CAM. 11266.

López-Mesa, B., Pitarch, A., Tomás, A., Gallego, T., 2009. Comparison of environmental impacts of building structures with in situ cast floors and with precast concrete floors. Building and Environment 44, 699-712. doi:10.1016/j . buildenv . 2008. 05.017.

Mao, C., Shen, Q., Shen, L., Tang, L., 2013. Comparative study of greenhouse gas emissions between off-site prefabrication and conventional construction methods: Two case studies of residential projects. Energy and Buildings 66, 165-176. doi:10. 1016/j.enbuild.2013.07.033.

Mason, J., 2018. Concrete block design query. Technical Report. Private communication.

Mathieu, P., 2006. The IPCC special report on carbon dioxide capture and storage, pp. $1611-1618$. 
McEvoy, D., Ravetz, J., Handley, J., 2004. Managing the Flow of Construction Minerals in the North West Region of England. Journal of Industrial Ecology 8, 121-140. URL: http://onlinelibrary.wiley.com/doi/10.1162/ $1088198042442289 /$ abstract, doi:10.1162/1088198042442289.

Miller, D., Doh, J., Guan, H., Mulvey, M., Fragomeni, S., McCarthy, T., Peters, T., 2013. Environmental impact assessment of post tensioned and reinforced concrete slab construction. Faculty of Engineering and Information Sciences - Papers: Part A , 1009-1014URL: http://ro.uow.edu.au/eispapers/1541, doi:10.1201/ b15320-180.

Mineral Products Association, 2015a. Annual Cementitious 2001-2014. Technical Report. Mineral Products Association. URL: http://cement.mineralproducts . org/documents/annual-cementitious.pdf.

Mineral Products Association, 2015b. Concrete Design Guide - No. 7 Design of post-tensioned slabs. Technical Report. URL: https://www.istructe.org/ getattachment/121ff74a-3a1d-4bf0-a300-31c3a8505949/CDG.

Moynihan, M.C., Allwood, J.M., 2014. Utilization of structural steel in buildings. Proc. R. Soc. A 470, 20140170. URL: http://rspa.royalsocietypublishing.org/ content/470/2168/20140170, doi:10.1098/rspa.2014.0170.

Neal, F.R., 2002. Concrete industrial ground floors. Thomas Telford Publishing. URL: https://www.icevirtuallibrary.com/doi/book/10.1680/cigf . 31371, doi:10.1680/cigf.31371.

Obla, K., Hong, R., Lobo, C., Kim, H., 2017. Should minimum cementitious contents for concrete be specified? Transportation Research Record 2629, 1-8. doi:10.3141/ 2629-01.

Office for National Statistics, 2015. Construction Statistics Annual 
Tables. Technical Report. URL: https://www.ons.gov.uk/ businessindustryandtrade/constructionindustry/datasets/ constructionstatisticsannualtables.

Office for National Statistics, 2018a. Construction output in Great Britain: December 2017. Technical Report. URL: https://www.ons.gov . uk/businessindustryandtrade/constructionindustry/bulletins/ constructionoutputingreatbritain/december 2017.

Office for National Statistics, 2018b. CPA 08:EU:IM:CVM:BOP:SA: 23.5. Cement, lime \& plaster. URL: https://www.ons.gov.uk/ businessindustryandtrade/internationaltrade/timeseries/p3ux/ mq10.

Office for National Statistics, 2018c. IOP:23.5-6:Man of cement,lime,plaster \& art of concrete,cement, plaster:Weight. URL: https://www . ons .gov .uk/economy/ economicoutputandproductivity/output/timeseries/km34/diop.

van Oss, H.G., 2017. Cement - Statistics and Information. URL: https://minerals . usgs.gov/minerals/pubs/commodity/cement/mcs-2017-cemen.pdf.

Post Tensioning Association, . Developer. URL: http://www.posttensioning.co. uk/developer/.

UK Quality Ash Association, 2016. Ash Statistics for 2014. URL: $\quad$ http://www.ukqaa.org.uk/wp-content/uploads/ Annual-ash-statistics-2014-Public-domain-table-bar-chart.pdf.

RailOne, 2018. Concrete Sleepers. Technical Report. Rail.One. URL: https://www.railone.com/fileadmin/daten/05-presse-medien/ downloads/broschueren/en/ConcreteSleepers_2014_EN.pdf. 
RIBA, 2011. The Case for Space. Technical Report. Royal Institute of British Architects. URL: https://www.architecture.com/-/media/ gathercontent/space-standards-for-homes/additional-documents/ ribacaseforspace2011pdf .pdf.

Rimoldi, A., 2017. Cement and concrete flow. Technical Report. Private communication.

Schneider, M., Romer, M., Tschudin, M., Bolio, H., 2011. Sustainable cement production-present and future. Cement and Concrete Research 41, 642-650. URL: http://www.sciencedirect.com/science/article/pii/ S0008884611000950, doi:10.1016/j.cemconres.2011.03.019.

Scrivener, K., 2014. Options for the future of cement. Indian Concrete Journal 88, $11-21$.

Scrivener, K.L., 2018. Potential LC3 penetration. Obtained through private communication.

Soutsos, M.N., Tang, K., Millard, S.G., 2011. Use of recycled demolition aggregate in precast products, phase II: Concrete paving blocks. Construction and Building Materials 25, 3131-3143. URL: http://www.sciencedirect.com/science/ article/pii/S0950061810007014, doi:10.1016/j.conbuildmat.2010.12. 024

Summerbell, D., Khripko, D., Barlow, C., Hesselbach, J., 2017. Cost and carbon reductions from industrial demand-side management: Study of potential savings at a cement plant. Applied Energy 197, 100-113. doi:10.1016/j . apenergy . 2017.03. 083.

Sun, J.C., Wang, B.J., Zhao, W.Z., 2013. Experimental study on the impact of admixture for concrete heat of hydration and early-age contractile properties. Applied 
Mechanics and Materials 253-255, 385-389. doi:10.4028/www.scientific.net/ AMM . 253-255. 385.

Tang, K., Millard, S., Beattie, G., 2015. Early-age heat development in GGBS concrete structures. Proceedings of the Institution of Civil Engineers - Structures and Buildings 168, 541-553. URL: https://www.icevirtuallibrary.com/doi/full/10. 1680/stbu.14.00089, doi:10.1680/stbu.14.00089.

Tarmac, 2017. Proven Performance - One Blackfriars, Southwark, London. Technical Report. Tarmac. URL: http://www.tarmac.com/media/959418/ topflow-one-blackfriars-case-study.pdf.

Teh, S.H., Wiedmann, T., Castel, A., de Burgh, J., $2017 . \quad$ Hybrid life cycle assessment of greenhouse gas emissions from cement, concrete and geopolymer concrete in Australia. Journal of Cleaner Production 152, 312320. URL: http://www.sciencedirect.com/science/article/pii/ S0959652617305668, doi:10.1016/j.jclepro.2017.03.122.

UK, H., 2017. Lexicon, Islington, London EC1 - Project case study. Technical Report. Hanson UK. URL: https://www.hanson.co.uk/en/case-study/lexicon.

uK Government, 2010. English Housing Survey. Technical Report. URL: https://assets.publishing.service.gov.uk/government/ uploads/system/uploads/attachment_data/file/6703/1750754.pdf.

UK Government, 2016. Mineral extraction in Great Britain 2014. Technical Report. URL: https://assets.publishing.service.gov.uk/government/ uploads/system/uploads/attachment_data/file/505631/Mineral_ Extraction_in_Great_Britain_2014_final.pdf.

uK Government - Competition Commission, 2016. Aggregates, Cement and Ready- 
mix Concrete Market Investigation. URL: https://www.gov.uk/cma-cases/ aggregates-cement-and-ready-mix-concrete-market-investigation.

UK Government - Department for Business, Energy and Industrial Strategy, 2016. Final uK greenhouse gas emissions national statistics 1990-2015. Technical Report. UK Government. URL: https://www.gov.uk/government/statistics/ final-uk-greenhouse-gas-emissions-national-statistics-1990-2015.

Wang, W., Jiang, D., Chen, D., Chen, Z., Zhou, W., Zhu, B., 2016. A Material Flow Analysis (MFA)-based potential analysis of eco-efficiency indicators of China's cement and cement-based materials industry. Journal of Cleaner Production 112, 787-796. URL: http://www.sciencedirect.com/science/article/pii/ S0959652615008367, doi:10.1016/j.jclepro.2015.06.103.

Wassermann, R., Katz, A., Bentur, A., 2009. Minimum cement content requirements: A must or a myth? Materials and Structures/Materiaux et Constructions 42, 973-982. doi:10.1617/s11527-008-9436-0.

Wille, K., Boisvert-Cotulio, C., 2015. Material efficiency in the design of ultra-high performance concrete. Construction and Building Materials 86, 33-43. URL: http://linkinghub.elsevier.com/retrieve/pii/ S0950061815003451, doi:10.1016/j. conbuildmat.2015.03.087.

Woodward, R., Duffy, N., 2011. Cement and concrete flow analysis in a rapidly expanding economy: Ireland as a case study. Resources, Conservation and Recycling 55, 448-455. doi:10.1016/j.resconrec.2010.12.006.

World Business Council for Sustainable Development - Cement Sustainability Initiative, 2016. Getting the Numbers Right. URL: http://www.wbcsdcement.org/ GNR-2013/index.html.

Zhou, D., Wang, R., Tyrer, M., Wong, H., Cheeseman, C., $2017 . \quad$ Sustainable 
infrastructure development through use of calcined excavated waste clay as a supplementary cementitious material. Journal of Cleaner Production 168, 11801192. URL: https://pureportal.coventry.ac.uk/en/publications/ sustainable-infrastructure-development-through-use-of-calcined-ex, doi:10.1016/j.jclepro.2017.09.098. 